\title{
Features of the Chronic Care Model (CCM) Associated with Behavioral Counseling and Diabetes Care in Community Primary Care
}

\author{
Pamela A. Obman Strickland, PhD, Shawna V. Hudson, PhD, Alicja Piasecki, MPH, \\ Karissa Hahn, MPH, Deborah Cohen, PhD, A. John Orzano, MD, MPH, \\ Michael L. Parchman, MD, and Benjamin F. Crabtree, PhD
}

Background: The Chronic Care Model (CCM) was developed to improve chronic disease care, but it may also inform delivery of other types of preventive care. Using hierarchical analyses of service delivery to patients, we explored associations of CCM implementation with diabetes care and counseling for diet or weight loss and physical activity in community-based primary care offices.

Methods: Secondary analysis focused on baseline data from 25 practices (with an average of 4 physicians per practice) participating in an intervention trial targeting improved colorectal cancer screening rates. This intervention made no reference to the CCM. CCM implementation was measured through staff and clinical management surveys and was associated with patient care indicators (chart audits and patient questionnaires).

Results: Overall, practices had low levels of CCM implementation. However, higher levels of CCM implementation were associated with better diabetes assessment and treatment of patients $(P=.009$ and .015 , respectively), particularly among practices open to "innovation." Physical activity counseling for obese and, particularly, overweight patients was strongly associated with CCM implementation $(P=$ $.0017)$, particularly among practices open to "innovation"; however, this association did not hold for overweight and obese patients with diabetes.

Conclusions: Very modest levels of CCM implementation in unsupported primary care practices are associated with improved care for patients with diabetes and higher rates of behavioral counseling. Incremental incorporation of CCM components is an option, especially for community practices with stretched resources and with cultures of "innovativeness." (J Am Board Fam Med 2010;23:295-305.)

Keywords: Primary Health Care, Chronic Disease, Diabetes, Chronic Care Model

The Chronic Care Model (CCM) provides a blueprint for changing office systems to improve chronic illness care. ${ }^{1-4}$ The CCM focuses on improving and optimizing 6 key elements of the health care system: health care organization, deliv-

This article was externally peer reviewed.

Submitted 3 June 2009; revised 30 October 2009; accepted 5 November 2009.

From the Departments of Biostatistics (PAOS) and Epidemiology (BFC), University of Medicine and Dentistry of New Jersey, School of Public Health, Piscataway; the Department of Family Medicine (PAOS, SVH, AP, KH, DC, BFC) and the Cancer Institute of New Jersey (PAOS, SVH, BFC), University of Medicine and Dentistry of New Jersey-Robert Wood Johnson Medical School, New Brunswick, NJ; the Department of Family Medicine, Dartmouth, Concord, NH (AJO); the South Texas Veterans Health Care System, San Antonio, TX (MLP); and the Center for Research in Family Practice and Primary Care, Cleveland, $\mathrm{OH}$, (BFC). ery system design, clinical information systems, decision support, self-management support, and community resource linkages. ${ }^{5-8}$ Together, these 6 elements are hypothesized to produce effective interactions between proactive, prepared primary care practice teams and informed, activated patients. ${ }^{6,8}$

Funding: Research was supported by the National Cancer Institute (R01 CA11287), an American Academy of Family Physicians' Research Center grant, and the Cancer Institute of New Jersey's Primary Care Research shared resource.

Conflict of interest: none declared.

Corresponding author: Pamela A. Ohman Strickland, PhD, Department of Biostatistics, UMDNJ-SPH, 683 Hoes Lane West, Room 218, P.O. Box 9, Piscataway, NJ 08854 (Email: ohmanpa@umdnj.edu). 
A number of studies show that when care is consistent with the elements of the CCM quality of life and outcomes for patients with diabetes are better. ${ }^{1,4,7,9-13}$ The CCM may also be a pragmatic model for improving delivery of preventive services. ${ }^{3,14,15}$ Hung et al ${ }^{14}$ examined the usefulness of the CCM for addressing health risk behaviors related to tobacco, alcohol, diet, and physical activity. Their research ${ }^{14}$ and the work of others ${ }^{3,15}$ suggest that the CCM may provide a useful framework for addressing these risk behaviors, reducing the gap between recommended and actual health promotion in primary care.

Complete implementation of the CCM, however, proves challenging. ${ }^{14,16}$ It is unclear whether comprehensive implementation of the CCM results in better outcomes than implementation of various individual elements. ${ }^{1,17} \mathrm{We}$ do not know if some elements result in better improvements in chronic care delivery than others. ${ }^{1,18}$ Further, most of the studies that examine the effectiveness of the CCM do so in primary care offices within larger health care systems (eg, academic medical centers; large, multispecialty groups; or federally funded community health centers). ${ }^{7,9,10,19-22}$ Little research addresses the effectiveness of the CCM in small, independent primary care practices that typically lack formal infrastructure ${ }^{1,4,23}$ to support quality improvement efforts. Yet redesign and medical home initiatives that incorporate CCM features $^{24,25}$ are increasingly being envisioned as paths to improving care.

This study examined whether offices that incorporate more features of the CCM deliver better diabetes care and more counseling for diet or weight loss and physical activity in community-based primary care settings. Specifically, we tested the following hypotheses. First, family medicine practices that incorporate more features of the CCM will have better delivery of care for patients with diabetes and better behavioral counseling for overweight and obese patients. Second, practices with leadership that is open to innovation will see greater effectiveness of other CCM features with respect to behavioral counseling for overweight and obese patients.

\section{Methods}

\section{Study Design}

This secondary analysis evaluated cross-sectional, baseline data that was collected in 2006 and 2007 for a quality improvement intervention study: Sup- porting Colorectal Cancer Outcomes through Participatory Enhancements. Data included practice and patient characteristics as well as measures of practice organization and the care delivered to patients.

Specifically, 30 consecutive patients age 50 and older were recruited from each of 25 practices. After informed consent was obtained, each patient completed a patient survey, providing the following personal information: race, age, height, health status, perceived continuity of care within the practice, and receipt of diet, weight loss, or physical activity counseling during the past year by either a clinician or someone else within the practice. Reviews of medical records were conducted by trained research nurses and were used to obtain information concerning the presence of comorbidities and most recent weight. In addition, medical record reviews provided information about diabetes assessment, treatment, and achievement of intermediate outcomes among patients with diabetes. Height and weight, obtained from the patient survey and chart audit, respectively, were used to calculate body mass index (BMI).

To collect practice-level information, the lead physician completed a Clinical Management Survey with items about practice organization and services provided to patients to assist with behavioral change. Each staff member was asked to complete a Practice Staff Questionnaire (PSQ), which provided perceptions of practice organization; this included the practice's openness to change. Within the PSQ, clinicians and clinical staff were asked additional questions concerning the use of tools for decision making and organizing patient care.

This project was approved by the University of Medicine and Dentistry of New Jersey's Institutional Review Board. Written, informed consent was obtained from the head physician at each practice and from each patient. Consent was implied for any of remaining practice staff who completed the CMS and PSQ. Practice staff received a \$5 gift card to Walmart or Blockbuster Video as an incentive for completing the PSQ.

\section{Measures for Hierarchical Analyses}

Practice Implementation of CCM

Relevant items from all survey instruments were identified and sorted according to the definitions of the components of the CCM; the Assessment of Chronic Illness Care $^{5}$ (ACIC) provided guidelines 
for classification. The ACIC was originally designed to measure the adoption of 6 components of CCM for practices engaging in interventions and was specifically aimed at integrating the CCM into practice. Specifically, the 2 primary authors (PAOS, SVH) created a draft sorting of items, which was then vetted and modified by the team during a series of 3 meetings. Table 1 provides definitions of each CCM component and the items selected from our instruments (along with the sources for those items) that operationalize practice characteristics regarding CCM implementation. A couple of modifications have been made from the CCM/ACIC. In particular, the original component relating to the Organization of Health Care Delivery System was modified to reflect Practice Organization, focusing on the practices' openness to "innovation"- - a culture that embraces change and learning. The Community Linkages component was not assessed in this study; previous experience demonstrated community linkages within these practices were rare so it made little sense to collect detailed information about this component. Behavior Change Support focused on items indicating direct communication with patients surrounding risky behavior and managing their own health. Some items could have been classified as either Delivery System Design or Clinical Information Systems (eg, registries for chronic diseases). Those items that pertained to mechanistic systems for organizing patient or visit information, such as registries, were classified under Clinical Information Systems. Items that directly affected communication between staff or reflected continuity of care were classified as Delivery System Design. Finally, Decision Support focused on items that provided general, non-patient-specific information to aid clinicians in understanding how to provide better care to their patients.

For all items, practice-level values were merged into a single data set (taking averages of responses from patient or practice staff members when appropriate). Because items were measured on different scales ranging from binary to a 5 -point Likert scale, $\mathrm{z}$ scores were created for each item to ensure comparability across items within a practice. Practice-level scores for each of the 5 CCM components were created by taking the average of the relevant items' z scores. This approach provides roughly equal weighting for items within each CCM component. Comprehensive CCM imple- mentation was represented by an average of the component scores for each practice.

\section{Patient Services}

These measures represent services at the patient level, which will be used as the outcomes of interest for this study. Receipt (Yes/No) of either diet or weight-loss counseling and physical activity counseling within the last year were obtained from patient surveys. Assessment (whether glycated hemoglobin [HbA1c] was assessed within the last 6 months, low-density lipoprotein [LDL] was assessed within last 12 months, and blood pressure checked during each of the last 3 visits); treatment (HbA1c $<7.0 \geq 7.0$ and taking hypoglycemic medication, LDL $\leq 100$ or $>100$ and taking lipid lowering medication, and blood pressure $\leq 130 / 85$ or, if not, taking hypertensive medication); and the attainment of at least 2 out of 3 intermediate outcomes (HbA1c <7.0, LDL $\leq 100$, and blood pressure $\leq 130 / 85)$ for diabetes patients were obtained from medical review.

\section{BMI}

Each patient's BMI was calculated (weight $[\mathrm{kg}] /$ height $\left[\mathrm{m}^{2}\right]$ ) using self-reported height and last recorded weight (from the medical record) and was classified as normal $(<25)$, overweight $(25$ to $<30)$, or obese $(\geq 30)$. This variable was used to identify the population of patients who were overweight or obese.

\section{Statistical Methods}

Summary statistics of patient-level characteristics, calculated as means and SDs for continuous variables or frequencies for categorical variables, were calculated for all patients as well as for subsets of patients who were overweight, obese, or had diabetes. Similar statistics were calculated for the practice descriptors.

Hierarchical logistic regression examined the association between delivery of services or achievement of intermediate outcomes at the patient level and the level of CCM implementation at the practice level. Specifically, generalized estimating equations $^{26,27}$ using a working correlation matrix with exchangeable structure modeled log-odds of service delivery as a function of practice- and patient-level covariates. These analyses, though using the patient as the unit of analysis, controlled for the nesting of patients within practice and appropri- 


\begin{tabular}{|c|c|c|c|}
\hline Term & Definition & $\begin{array}{c}\text { Average Practice Score } \\
\text { (SD) }\end{array}$ & Descriptive Items \\
\hline Practice organization & $\begin{array}{l}\text { An organization that provides } \\
\text { safe, high-quality care with } \\
\text { leadership that encourages } \\
\text { efforts to improve care }\end{array}$ & $0.04(1.00)$ & $\begin{array}{l}\text { - People in our practice actively seek new } \\
\text { ways to improve how we do things. } \\
\text { - The practice leadership makes sure that } \\
\text { we have the time and space necessary } \\
\text { to discuss changes to improve care. }{ }^{\dagger} \\
\text { - Most people in this practice are willing } \\
\text { to change how they do things in } \\
\text { response to feedback from others. }\end{array}$ \\
\hline Behavioral change support & $\begin{array}{l}\text { Effective behavior change } \\
\text { support is used to help } \\
\text { patients and families } \\
\text { improve their health } \\
\text { behavior }\end{array}$ & $0.00(0.43)$ & $\begin{array}{l}\text { - Use of patient questionnaire at either } \\
\text { the first visit or routine visits to } \\
\text { identify patients who may benefit from } \\
\text { counseling for eating habits, physical } \\
\text { activity, smoking, alcohol use and } \\
\text { cancer screening (maximum across first } \\
\text { and routine-use responses and then } \\
\text { averaged across behavior categories). } \\
\text { - Refer out for counseling or screening } \\
\text { (averaged across behavior categories). } \\
\text { - Use nurses or health educators within } \\
\text { the practice for individual counseling } \\
\text { or use group counseling activities } \\
\text { (averaged across behavior categories). } \\
\text { - Frequency with which practices use a } \\
\text { process or system for reminding } \\
\text { patients about visits. }{ }^{\S}\end{array}$ \\
\hline Delivery system design & $\begin{array}{l}\text { Organizational features of the } \\
\text { practice assure well- } \\
\text { planned visits and impact } \\
\text { the provision of care }\end{array}$ & $0.00(0.46)$ & $\begin{array}{l}\text { - Frequency of clinical meetings. } \\
\text { - Inclusion of staff members with } \\
\text { different roles in the clinical } \\
\text { meetings. }{ }^{\text {Il }} \\
\text { - Continuity of care: When patient gets } \\
\text { sick, they contact the practice first } \\
\text { (before going to specialist or } \\
\text { emergency room)** }\end{array}$ \\
\hline Decision support & $\begin{array}{l}\text { Clinicians have convenient } \\
\text { access to the latest } \\
\text { evidence-based guidelines } \\
\text { and specialist expertise is } \\
\text { integrated into the practice }\end{array}$ & $0.04(0.57)$ & $\begin{array}{l}\text { - Computers are used for retrieving } \\
\text { information, either through PDAs, online } \\
\text { literature searching, a CD-based medical } \\
\text { knowledge base or the Internet } \\
\text { - Use of chart audit for chronic diseases or } \\
\text { cancer screening } \\
\text { - Use of nurses and health educators }\end{array}$ \\
\hline Clinical information systems & $\begin{array}{l}\text { Data about patients is } \\
\text { organized to facilitate } \\
\text { efficient and effective care }\end{array}$ & $0.01(0.77)$ & $\begin{array}{l}\text { - A registry for chronic diseases. } \\
\text { - A process for identifying patients due } \\
\text { for screening or tests. } \\
\text { - A process to prompt clinicians at the } \\
\text { time of visits about needed tests or } \\
\text { additional visits. }{ }^{\ddagger} \\
\text { - Risk factor chart stickers or electronic flags } \\
\text { - } \text { Checklists or flowcharts }^{\ddagger}\end{array}$ \\
\hline
\end{tabular}

*Average component scores were created as an average of z-scores from items used to assess each component.

†Practice Staff Questionnaire (PSQ), each item scored on a 1 to 5 scale, "strongly disagree" to "strongly agree."

"PSQ, each item scored on a 1 to 5 scale, "never used" to "always used."

${ }^{\S}$ Clinical Management Survey (CMS), scored on a 1 to 5 scale, "never used" to "always used."

"CMS, scored on a 1 to 5 scale, "weekly," "monthly," "quarterly," "annually," "never."

${ }^{\mathbb{I}} \mathrm{CMS}$, a count of the types of staff in attendance: physicians, other clinicians, nursing staff, office staff.

**Patient survey, scored 1 to 5, "never" to "always."

${ }^{\dagger}$ PSQ, 0 or 1 for "not used" or "used."

PDA, personal digital assistant.

ately tested for the significance of both patient- and practice-level variables.

For hypothesis 1 , only patients with diabetes $(\mathrm{n}=196)$ or patients who were overweight or obese $(n=491)$ were included in the analyses. The average of the practice-level scores for each of the 5 CCM components was used as a comprehensive measure of CCM implementation to predict service 
delivery. Secondary analyses for this hypothesis evaluated the individual components simultaneously within a single model. For each of these predictors, odds ratios (ORs) and 95\% CIs were estimated comparing the effectiveness for practices in the 25th and 75th percentiles of CCM implementation in delivering services. Post hoc analyses stratified these results to examine separately counseling for patients who did and did not have diabetes.

For hypothesis 2, practices were stratified using a median split on the Practice Organization component as being "high" or "low" on openness to innovation. Analyses similar to those described above examined the association of the average of the 4 remaining CCM components with service delivery within each group of practices. Odds ratios estimated the effect of CCM implementation (comparing the 25th and 75 th percentiles of implementation of the 4 remaining CCM components) and service delivery among practices more and less open to innovation.

All analyses included age, sex, obesity status, general health status, and whether the patient had diabetes (included as appropriate), hypertension, or a heart condition as patient-level covariates and whether the practice used an electronic medical record or not as a practice-level covariate. All analyses were conducted using the SAS/STAT software (SAS system for Windows, version 9.1.3; SAS Institute Inc, Cary, NC).

\section{Results}

Table 2 presents patient characteristics. Of the 25 practices, 23 (92\%) had 2 or more physicians; the average number of physicians was 4.28 (SD, 3.10). Practices had been in existence for an average of 11 years (SD, 8.5).

Means and SDs for the CCM component scores are given in Table 1. Of interest, the CCM components had varying levels of correlation with one another, with only one significant correlation (0.61) between Decision Support and Behavioral Change Support $(P=.0013)$. Decision support was also marginally associated with openness to change $(\mathrm{r}=$ $0.35 ; P=.089)$ and Clinical Information Systems ( $\mathrm{r}=0.37 ; P=.066)$; Behavioral Change Support was marginally associated with Clinical Information Systems $(\mathrm{r}=0.36 ; P=.074)$. All other correlations $(\mathrm{r}<0.18)$ had $P>.40$.

\section{Hypothesis 1 (Table 3)}

For patients with diabetes, increased CCM implementation was significantly associated with increased assessment of HbA1c, lipids, and blood pressure $(\mathrm{OR}=1.90, P=.009)$ and with treatment for HbA1c, lipids and blood pressure (OR, 1.79; $P=.015)$. For example, the odds of appropriate assessment for patients with diabetes were $90 \%$ greater for practices in the 75 th percentile of CCM implementation relative to those in the 25 th percentile. The relationships of achievement of targets as well as counseling for diet/weight loss or physical activity among diabetic patients with CCM implementation were not significant.

However, for all obese and overweight patients, including those with and without diabetes, CCM implementation was associated with physical activity counseling $(P=.0017)$ but not diet or weightloss counseling $(P=.31)$. The odds of counseling for physical activity were $35 \%$ higher for patients in practices at the 75 th percentile of CCM implementation relative to those in the 25 th percentile. This $\mathrm{OR}$ is comparable to the magnitude of those for assessment, treatment, and achievement of targets for patients with diabetes (also shown in Table 3).

In additional analyses to understand the discrepancy between results for counseling among patients with diabetes and among overweight/obese patients, the latter category was broken down into 2 groups: patients with diabetes and patients without diabetes. Overall CCM implementation was significantly associated with physical activity counseling among obese/overweight patients without diabetes (OR, 1.51; $P=.0017)$, but not among obese/overweight patients with diabetes $(P=.76)$.

\section{Hypothesis 2 (Table 4)}

Among practices with low scores on Practice Organization, defined as "open to innovation," there was no effect of the remaining CCM components on the outcomes of interest either for patients with diabetes or for obese or overweight patients. However, the level of implementation of the remaining CCM components was associated with appropriate assessment, treatment, and attainment of targets among patients with diabetes $(P=.042, .0033$, and .012 , respectively). In addition, among practices that were more open to innovation, physical activity counseling was more likely to occur for patients who were obese or overweight in practices with increased CCM implementation $(P=.0006)$. 
Table 2. Characteristics of the Combined Sample of 674 Patients Sampled Across 25 SCOPE Practices, Along with Summaries of Subpopulations of Patients Within Each Weight Category as Well as of Patients with Diabetes (Regardless of Weight Status)

\begin{tabular}{|c|c|c|c|c|c|}
\hline Patient Characteristic & $\begin{array}{l}\text { Overall } \\
(\mathrm{n}=674)\end{array}$ & $\begin{array}{l}\text { Normal } \\
(\mathrm{n}=183)\end{array}$ & $\begin{array}{c}\text { Overweight } \\
(\mathrm{n}=218)\end{array}$ & $\begin{array}{c}\text { Obese } \\
(\mathrm{n}=273)\end{array}$ & $\begin{array}{l}\text { Diabetic } \\
(\mathrm{n}=196)\end{array}$ \\
\hline Age $^{*}$ & $64.1(10.1)$ & $64.21(11.5)$ & $66.0(10.3)$ & $62.5(8.6)$ & $64.9(10.0)$ \\
\hline Sex (male) & $267(39.6)$ & $58(31.7)$ & $108(49.5)$ & $101(37.0)$ & $89(45.4)$ \\
\hline \multicolumn{6}{|l|}{ Race } \\
\hline White & $471(69.9)$ & $142(77.6)$ & $148(67.9)$ & $181(66.3)$ & $105(53.6)$ \\
\hline Black & $121(18.0)$ & $18(9.8)$ & $40(18.4)$ & $63(23.1)$ & $59(30.1)$ \\
\hline Hispanic & $46(6.8)$ & $6(3.3)$ & $22(10.1)$ & $18(6.6)$ & $16(8.2)$ \\
\hline Other & $32(4.8)$ & $16(8.7)$ & $6(2.8)$ & $10(3.7)$ & $12(6.1)$ \\
\hline Unknown & $4(0.6)$ & $1(0.6)$ & $2(0.9)$ & $1(0.4)$ & $4(2.0)$ \\
\hline \multicolumn{6}{|l|}{ Education } \\
\hline$<$ High school & $72(10.7)$ & $14(7.7)$ & $22(10.1)$ & $36(13.2)$ & $33(16.8)$ \\
\hline High school or some college & $326(48.4)$ & $71(38.8)$ & $106(48.6)$ & $149(54.6)$ & $101(51.5)$ \\
\hline College or graduate school & $273(40.5)$ & $97(53.0)$ & $90(41.3)$ & $86(31.5)$ & $60(30.6)$ \\
\hline Unknown & $3(0.5)$ & $1(0.6)$ & $0(0)$ & $2(0.7)$ & $2(1.0)$ \\
\hline \multicolumn{6}{|l|}{ Marital status } \\
\hline Married & $424(62.9)$ & $114(62.3)$ & $150(68.8)$ & $160(58.6)$ & $111(56.6)$ \\
\hline Not married & $250(37.1)$ & $69(37.7)$ & $68(31.2)$ & $113(41.4)$ & $85(43.4)$ \\
\hline \multicolumn{6}{|l|}{ Insurance status } \\
\hline Medicare & $257(38.1)$ & $68(37.2)$ & $88(40.4)$ & $101(37.0)$ & $84(42.9)$ \\
\hline Medicaid & $33(4.9)$ & $5(2.7)$ & $11(5.1)$ & $17(6.2)$ & $13(6.6)$ \\
\hline Private & $317(47.0)$ & $97(53.0)$ & $99(45.4)$ & $121(44.3)$ & $74(37.8)$ \\
\hline Other & $30(4.5)$ & $7(3.83 .0)$ & $9(4.1)$ & $14(5.1)$ & $7(3.6)$ \\
\hline None & $29(4.3)$ & $4(2.2)$ & $10(4.6)$ & $15(5.5)$ & $18(9.2)$ \\
\hline Unknown & $8(1.2)$ & $2(1.1)$ & $1(0.5)$ & $5(1.8)$ & $0(0)$ \\
\hline Global health* & $2.29(0.61)$ & $2.16(0.62)$ & $2.26(0.64)$ & $2.41(0.55)$ & $2.54(0.54)$ \\
\hline Physical health* & $2.34(0.63)$ & $2.16(0.66)$ & $2.30(0.64)$ & $2.50(0.57)$ & $2.65(0.54)$ \\
\hline Emotional health* & $2.14(0.66)$ & $2.11(0.61)$ & $2.06(0.69)$ & $2.22(0.66)$ & $2.30(0.67)$ \\
\hline Visits during past 2 years $(\mathrm{n})^{*}$ & $7.57(5.29)$ & $6.64(4.62)$ & $7.42(4.77)$ & $8.32(5.97)$ & $8.73(5.94)$ \\
\hline Diabetes assessment & - & - & - & - & $91(46.4)$ \\
\hline Diabetes treatment & - & - & - & - & $99(50.5)$ \\
\hline $\begin{array}{l}\text { At least } 2 \text { out of } 3 \text { diabetes outcomes at } \\
\text { target }\end{array}$ & - & - & - & - & $84(42.9)$ \\
\hline Received diet or weight loss counseling & - & - & $118(53.4)$ & $212(77.7)$ & $137(69.90)$ \\
\hline Received physical activity counseling & - & - & $127(57.5)$ & $191(70.0)$ & $137(69.90)$ \\
\hline
\end{tabular}

Data presented as $\mathrm{n}(\%)$ unless otherwise indicated.

${ }^{*}$ Data presented as mean (SD).

- , these $\mathrm{n}(\%)$ are not provided as these services or targets are not recommended per guidelines for these groups of patients.

\section{Discussion}

In this study, patients with diabetes who were seen in practices that have implemented more CCM features were significantly more likely to receive appropriate diabetes care. In addition, physical activity counseling for overweight/obese patients was more likely to occur in primary care practices where more CCM features were implemented, particularly within practices reporting leadership that was more open to "innovation" or among obese or overweight patients without diabetes. However, no association was seen between the implementation of CCM features and weight-loss or diet counseling.

Although associations were strongest and most significant when the CCM was considered as a whole rather than subdivided into components, correlations between components of the CCM were small to moderate. This suggests, as reported by others, ${ }^{1}$ that none of the individual components are universally important; rather, small efforts in several of the component areas or a major effort 


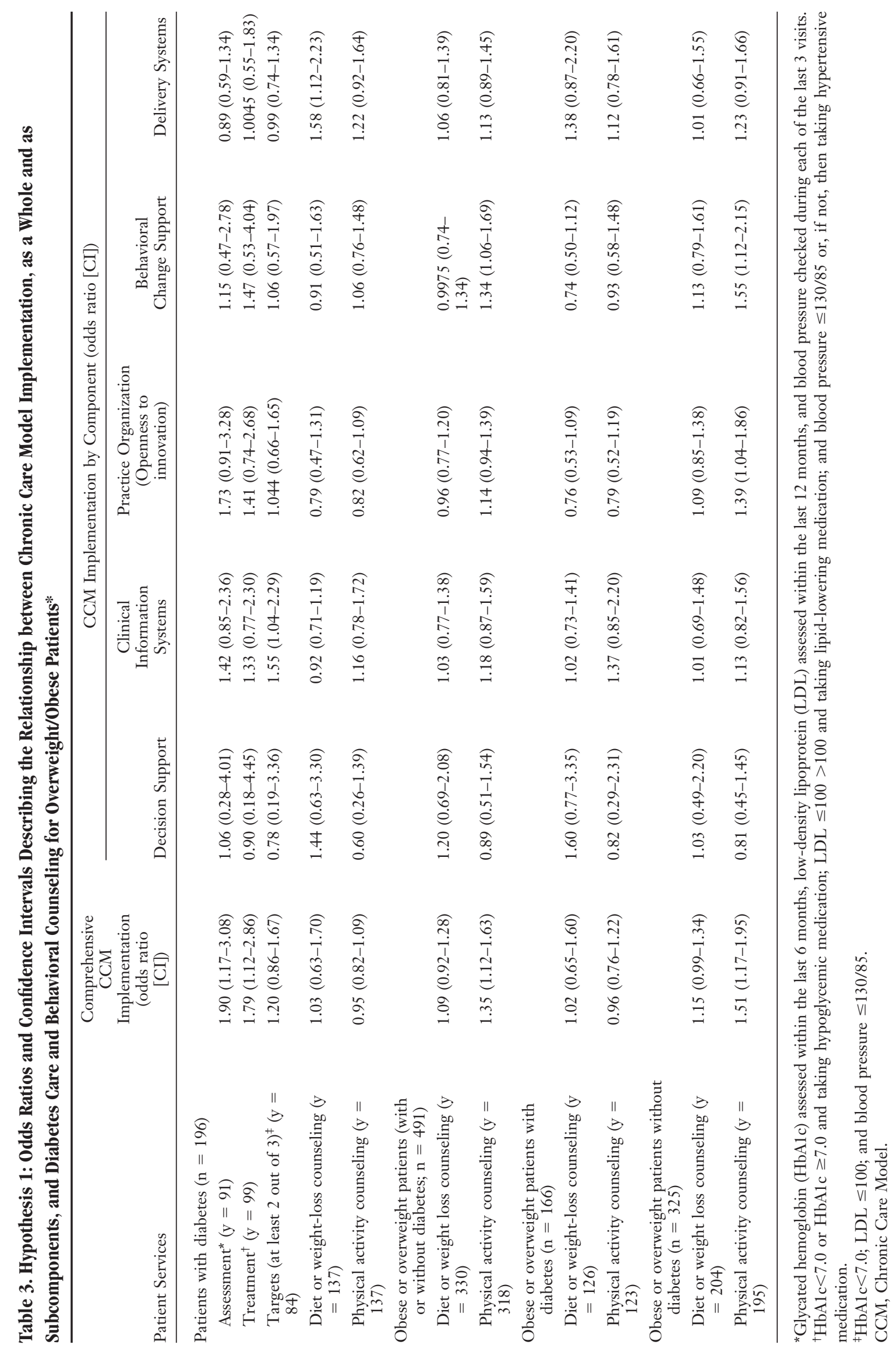


Table 4. Hypothesis 2: Odds Ratios and Confidence Intervals Describing the Relationship between Chronic Care Model Implementation and Diabetes Care and Behavioral Counseling for Overweight/Obese Patients for Practice with Low and High Levels of Openness to Innovation*

\begin{tabular}{|c|c|c|}
\hline \multirow[b]{2}{*}{ Patient Services } & \multicolumn{2}{|c|}{$\begin{array}{l}\text { Openness to Innovation among Practices } \\
\text { (odds ratio [CI]) }\end{array}$} \\
\hline & Low & High \\
\hline \multicolumn{3}{|l|}{ Patients with diabetes $(\mathrm{n}=196)$} \\
\hline Assessment $^{\dagger}$ & $1.52(0.79-2.92)$ & $1.84(1.02-3.32)$ \\
\hline Treatment $^{\ddagger}$ & $2.09(0.77-5.66)$ & $2.06(1.27-3.34)$ \\
\hline Target (at least 2 out of 3$)^{\S}$ & $1.19(0.51-2.76)$ & $1.71(0.13-2.58)$ \\
\hline Diet or weight loss counseling & $1.27(0.71-2.26)$ & $1.19(0.73-1.95)$ \\
\hline Physical activity counseling & $1.17(0.73-1.87)$ & $1.30(0.91-1.87)$ \\
\hline \multicolumn{3}{|c|}{$\begin{array}{l}\text { Obese or overweight patients (with or without } \\
\text { diabetes; } \mathrm{n}=491 \text { ) }\end{array}$} \\
\hline Diet or weight loss counseling & $1.15(0.97-1.37)$ & $1.03(0.86-1.25)$ \\
\hline Physical activity counseling & $1.30(0.94-1.79)$ & $1.60(1.23-2.09)$ \\
\hline
\end{tabular}

*Odds ratios represent the odds of appropriate service for patients within practices at the 75 th percentile versus the 25 th percentile of implementation of either the comprehensive Chronic Care Model or its components.

${ }^{\dagger}$ Glycated hemoglobin (HbA1c) assessed within the last 6 months, low-density lipoprotein (LDL) assessed within the last 12 months, and blood pressure (BP) checked during each of the last 3 visits.

${ }^{\ddagger} \mathrm{HbAl}<7.0$ or HbAlc $\geq 7.0$ and taking hypoglycemic medication; LDL $\leq 100$ or LDL $>100$ and taking lipid-lowering medication; and $\mathrm{BP} \leq 130 / 85$ or, if not, then taking hypertensive medication.

${ }^{\S} \mathrm{HbAlc}<7.0 ; \mathrm{LDL} \leq 100$; and $\mathrm{BP} \leq 130 / 85$.

within one component may be acceptable ways to incorporate CCM features into community primary care practices and to enhance patient care. ${ }^{22}$ This finding is consistent with the idea that primary care practices are complex adaptive systems where a "one-size-fits-all" approach is unlikely to be successful. ${ }^{28,29}$ Each practice may incorporate features of the CCM in their practice that are most consistent with their resources, values, and culture, resulting in improved patient care for that unique practice.

The effectiveness of the CCM may be diminished when psychosocial barriers or competing demands are strong. For example, in this study, with rates of counseling for diet or weight-loss counseling already relatively high for overweight and obese patients $(67 \%)$ as compared with previously published studies, ${ }^{28,29}$ persistent barriers already recognized in the literature may limit any additional improvement because of the CCM. For example, despite comprehensive published guidelines ${ }^{30,31}$ aimed at increasing the frequency of weight counseling, physicians report feeling poorly prepared to effectively recommend weight-management strategies or to develop and implement weight-reduction and treatment plans. ${ }^{32-35}$ Further, although weight and obesity are delicate topics, ${ }^{35,36}$ talking about physical activity may be a way to broach the subject indirectly. This less direct approach may encounter fewer barriers and be more easily influenced by the implementation of mechanistic procedures intended to motivate physicians. Similar explanations may be found to explain why CCM implementation is effective in improving rates of physical activity counseling among patients without diabetes but not patient with diabetes. In this case, during the encounter the competing demands of providing care to manage diabetes, its complications, or other chronic diseases may provide barriers to counseling that are difficult to overcome. ${ }^{37}$

A study finding that has potential broad-reaching implication-not just for CCM implementation but also for implementing other quality-improvement models for care, practice redesign efforts, or medical home initiatives-is that a practice's openness to innovation can impact how effective a model is for improving care. Existing literature identifies characteristics of practice organization $^{38,39}$ that may inform these processes, such as the nature of relationships among practice members, ${ }^{40,41}$ the practice members' ability to work as a team, ${ }^{42}$ and how a practice manages knowledge. ${ }^{43}$ Thus, regardless of the model for change that will be used, consideration needs to be given to the development of a practice's organizational systems to innovate and deliver high-quality 
care, ${ }^{44}$ whether it be chronic disease management or health promotion advice and services.

A number of limitations exist for this study. Because this study was an observational, cross-sectional study rather than a clinical trial, inference of causation is not appropriate. Several clinical trials have been conducted or are underway that examine full CCM implementation within primary care practices. $^{23,45,46}$ Additional studies have found improved patient care after CCM implementation using study designs that address patient care before and after implementation. ${ }^{47,48}$

Another limitation is the small sample $(\mathrm{n}=25)$ of mostly privately owned practices located in New Jersey; because of this our results may not be broadly generalizable. However, of all communitybased primary care practices in the United States, approximately two thirds have 5 or fewer physicians. ${ }^{49}$ Further, the results found here reflect those from other studies. ${ }^{50}$ As an additional limitation, the instruments were not specifically designed to measure CCM implementation. Thus, our measurement of CCM characteristics within practices in this secondary analysis may include both theoretical and measurement error with respect to the true intent of the CCM. However, practices in this study did not seek to implement the CCM or even have direct knowledge of the model. A review of qualitative data validated that practices enrolled in this study had very minimal levels of CCM implementation, most of which were captured in our surveys.

This study focused on small, mostly privately owned primary care practices (typical of the majority of primary care settings in the United States), many of which were struggling with the basic issues related to financial solvency and staff turnover. There are a number of studies that look at weight counseling in idealized settings, ${ }^{51-54}$ yet few studies adequately examine the delivery of weight counseling in the primary care setting, ${ }^{55-58}$ where most people receive their care most of the time. The level of CCM implementation witnessed in this study was quite low relative to the ideal as described in the ACIC. Although this may be seen as a weakness of this study, the fact that we saw effects of such low levels of CCM implementation is extremely promising in that an ordinary primary care practice that is open to innovation may not need to invest large amounts of capital and other resources or implement the complete CCM to see positive results.

\section{References}

1. Nutting PA, Dickinson WP, Dickinson LM, et al. Use of chronic care model elements is associated with higher-quality care for diabetes. Ann Fam Med 2007;5:14-20.

2. Glasgow RE, Hiss RG, Anderson RM, et al. Report of the health care delivery work group: behavioral research related to the establishment of a chronic disease model for diabetes care. Diabetes Care 2001; 24:124-30.

3. Glasgow RE, Orleans CT, Wagner EH. Does the chronic care model serve also as a template for improving prevention? Milbank Q 2001;79:579-612, iv-v.

4. Parchman ML, Pugh JA, Wang CP, Romero RL. Glucose control, self-care behaviors, and the presence of the chronic care model in primary care clinics. Diabetes Care 2007;30:2849-54.

5. Bonomi AE, Wagner EH, Glasgow RE, VonKorff M. Assessment of chronic illness care (ACIC): a practical tool to measure quality improvement. Health Serv Res 2002;37:791-820.

6. Bodenheimer T, Wagner EH, Grumbach K. Improving primary care for patients with chronic illness: the chronic care model. Part 2. JAMA 2002; 288:1909-14.

7. Schmittdiel J, Mosen DM, Glasgow RE, Hibbard J, Remmers C, Bellows J. Patient Assessment of Chronic Illness Care (PACIC) and improved patient-centered outcomes for chronic conditions. J Gen Intern Med 2008;23:77-80.

8. Wagner EH. Chronic disease management: what will it take to improve care for chronic illness? Eff Clinical Prac 1998;1:2-4.

9. Hess R, Bryce CL, Paone S, et al. Exploring challenges and potentials of personal health records in diabetes self-management: implementation and initial assessment. Telemed J E Health 2007;13:509_ 17 .

10. Kirsh S, Watts S, Pascuzzi K, et al. Shared medical appointments based on the chronic care model: a quality improvement project to address the challenges of patients with diabetes with high cardiovascular risk. Qual Saf Health Care 2007;16:349-53.

11. Orzano AJ, Strickland PO, Tallia AF, et al. Improving outcomes for high-risk diabetics using information systems. J Am Board Fam Med 2007;20:245-51.

12. Parchman ML, Zeber JE, Romero RR, Pugh JA. Risk of coronary artery disease in type 2 diabetes and the delivery of care consistent with the chronic care model in primary care settings: a STARNet study. Med Care 2007;45:1129-34.

13. Williams GC, Lynch M, Glasgow RE. Computerassisted intervention improves patient-centered dia- 
betes care by increasing autonomy support. Health Psychol 2007;26:728-34.

14. Hung DY, Rundall TG, Tallia AF, Cohen DJ, Halpin HA, Crabtree BF. Rethinking prevention in primary care: applying the chronic care model to address health risk behaviors. Milbank Q 2007;85:6991.

15. Lyznicki JM, Young DC, Riggs JA, Davis RM. Obesity: assessment and management in primary care. Am Fam Physician 2001;63:2185-96.

16. Hroscikoski MC, Solberg LI, Sperl-Hillen JM, Harper PG, McGrail MP, Crabtree BF. Challenges of change: a qualitative study of chronic care model implementation. Ann Fam Med 2006;4:317-26.

17. Renders CM, Valk GD, Griffin S, Wagner EH, Eijk JT, Assendelft WJ. Interventions to improve the management of diabetes mellitus in primary care, outpatient and community settings. Cochrane Database Syst Rev 2001:CD001481.

18. Sperl-Hillen JM, Solberg LI, Hroscikoski MC, Crain AL, Engebretson KI, O'Connor PJ. Do all components of the chronic care model contribute equally to quality improvement? Jt Comm J Qual Saf 2004;30:303-9.

19. Caruso LB, Clough-Gorr KM, Silliman RA. Improving quality of care for urban older people with diabetes mellitus and cardiovascular disease. J Am Geriatr Soc 2007;55:1656-62.

20. Solberg LI, Crain AL, Sperl-Hillen JM, Hroscikoski MC, Engebretson KI, O'Connor PJ. Care quality and implementation of the chronic care model: a quantitative study. Ann Fam Med 2006;4:310-6.

21. Gilmer TP, Philis-Tsimikas A, Walker C. Outcomes of Project Dulce: a culturally specific diabetes management program. Ann Pharmacother 2005;39:81722.

22. Pearson ML, Wu S, Schaefer J, et al. Assessing the implementation of the chronic care model in quality improvement collaboratives. Health Serv Res 2005; 40:978-96.

23. Piatt GA, Orchard TJ, Emerson S, et al. Translating the chronic care model into the community: results from a randomized controlled trial of a multifaceted diabetes care intervention. Diabetes Care 2006;29: 811-7.

24. Rogers JC. The patient-centered medical home movement-promise and peril for family medicine. J Am Board Fam Med 2008;21:370-4.

25. Rosenthal TC. The medical home: growing evidence to support a new approach to primary care. J Am Board Fam Med 2008;21:427-40.

26. Zeger SL, Liang KY. Longitudinal data analysis for discrete and continuous outcomes. Biometrics 1986; 42:121-30.

27. Lipsitz SR, Kim K, Zhao L. Analysis of repeated categorical data using generalized estimating equations. Stat Med 1994;13:1149-63.

28. Galuska DA, Will JC, Serdula MK, Ford ES. Are health care professionals advising obese patients to lose weight? JAMA 1999;282:1576-8.

29. Heath C, Grant W, Marcheni P, Kamps C. Do family physicians treat obese patients? Fam Med 1993;25:401-2.

30. Overweight, obesity, and health risk. National Task Force on the Prevention and Treatment of Obesity. Arch Intern Med 2000;160:898-904.

31. U.S. Preventive Services Task Force. Guide to clinical preventive services. 2nd ed. Baltimore, MD: Williams \& Wilkins; 1996.

32. Eaton CB, McBride PE, Gans KA, Underbakke GL. Teaching nutrition skills to primary care practitioners. J Nutr 2003;133:563S-6S.

33. Frank A. A multidisciplinary approach to obesity management: the physician's role and team care alternatives. J Am Diet Assoc 1998;98:S44-8.

34. Rippe JM, Crossley S, Ringer R. Obesity as a chronic disease: modern medical and lifestyle management. J Am Diet Assoc 1998;98:S9-15.

35. Ferrante JM, Piasecki AK, Ohman-Strickland PA, Crabtree BF. Family physicians' practices and attitudes regarding care of extremely obese patients. Obesity (Silver Spring) 2009;17:1710-6.

36. Johanson M, Larsson US, Saljo R, Svardsudd K. Lifestyle discussion in the provision of health care. An empirical study of patient-physician interaction. Soc Sci Med 1998;47:103-12.

37. Parchman ML, Pugh JA, Romero RL, Bowers KW. Competing demands or clinical inertia: the case of elevated glycosylated hemoglobin. Ann Fam Med 2007;5:196-201.

38. Orzano AJ, Tallia AF, Nutting PA, Scott-Cawiezell J, Crabtree BF. Are attributes of organizational performance in large health care organizations relevant in primary care practices? Health Care Manage Rev 2006;31:2-10.

39. Cohen D, McDaniel RR Jr, Crabtree BF, et al. A practice change model for quality improvement in primary care practice. J Healthc Manag 2004;49: 155-68, discussion 69-70.

40. Miller WL, Crabtree BF. Healing landscapes: patients, relationships, and creating optimal healing places. J Altern Complement Med 2005;11(Suppl 1):S41-9.

41. Tallia AF, Lanham HJ, McDaniel RR Jr, Crabtree BF. Seven characteristics of successful work relationships. Fam Pract Manag 2006;13:47-50.

42. Hudson SV, Ohman-Strickland P, Cunningham R, Ferrante JM, Hahn K, Crabtree BF. The effects of teamwork and system support on colorectal cancer screening in primary care practices. Cancer Detect Prev 2007;31:417-23.

43. Orzano AJ, McInerney CR, Tallia AF, Scharf D, Crabtree BF. Family medicine practice performance and knowledge management. Health Care Manage Rev 2008;33:21-8.

44. Woolf SH, Johnson RE. The break-even point: 
when medical advances are less important than improving the fidelity with which they are delivered. Ann Fam Med 2005;3:545-52.

45. Porter S. Focus on practice redesign, quality improvement. Ann Fam Med 2006;4:86-7.

46. Parchman ML, Pugh JA, Culler SD, et al. A group randomized trial of a complexity-based organizational intervention to improve risk factors for diabetes complications in primary care settings: study protocol. Implement Sci 2008;3:15.

47. Siminerio LM, Piatt G, Zgibor JC. Implementing the chronic care model for improvements in diabetes care and education in a rural primary care practice. Diabetes Educ 2005;31:225-34.

48. Siminerio LM, Piatt GA, Emerson S, et al. Deploying the chronic care model to implement and sustain diabetes self-management training programs. Diabetes Educ 2006;32:253-60.

49. Liebhaber A, Grossman JM. Physicians moving to mid-sized, single-specialty practices. Track Rep 2007;(18):1-5.

50. Coleman K, Austin BT, Brach C, Wagner EH. Evidence on the Chronic Care Model in the new millennium. Health Aff (Millwood) 2009;28:75-85.

51. Coates RJ, Bowen DJ, Kristal AR, et al. The Women's Health Trial Feasibility Study in minority populations: changes in dietary intakes. Am J Epidemiol 1999;149:1104-12.

52. Henderson MM, Kushi LH, Thompson DJ, et al. Feasibility of a randomized trial of a low-fat diet for the prevention of breast cancer: dietary compliance in the Women's Health Trial Vanguard Study. Prev Med 1990;19:115-33.

53. Knutsen SF, Knutsen R. The Tromso Survey: the family intervention study-the effect of intervention on some coronary risk factors and dietary habits, a 6-year follow-up. Prev Med 1991;20:197-212.

54. Mojonnier ML, Hall Y, Berkson DM, et al. Experience in changing food habits of hyperlipidemic men and women. J Am Diet Assoc 1980;77:140-8.

55. Ockene IS, Hebert JR, Ockene JK, et al. Effect of physician-delivered nutrition counseling training and an office-support program on saturated fat intake, weight, and serum lipid measurements in a hyperlipidemic population: Worcester Area Trial for Counseling in Hyperlipidemia (WATCH). Arch Intern Med 1999;159:725-31.

56. Beresford SA, Curry SJ, Kristal AR, Lazovich D, Feng Z, Wagner EH. A dietary intervention in primary care practice: the Eating Patterns Study. Am J Public Health 1997;87:610-6.

57. Beresford SA, Farmer EM, Feingold L, Graves KL, Sumner SK, Baker RM. Evaluation of a self-help dietary intervention in a primary care setting. Am J Public Health 1992;82:79-84.

58. Scott JG, Cohen D, DiCicco-Bloom B, et al. Speaking of weight: how patients and primary care clinicians initiate weight loss counseling. Prev Med 2004; 38:819-27. 